\title{
An Environmentally-oriented Mode of Industrial Project Planning
}

\author{
by
}

Thomas N. Gladwin, MBA, Ph.D.(Michigan)

$\&$

Michael G. Royston, Ph.D.(London)

Environmental Management Faculty, Centre d'Etudes Industrielles, 4 chemin de Conches, 1231 Conches, Geneva, Switzerland.

\section{INTRODUCTION}

The necessity of adding an ecological dimension to the management of industrial activities is well documented (Kapp, 1970; Commoner, 1971; Brubaker, 1972; Caldwell, 1972; Ward \& Dubos, 1972; Strong, 1973). Recent research has shown that the behaviour of industrial firms in planning their activitiesparticularly new production facilities-still largely ignores ecological consequences (Gladwin, 1975). Natural processes are often disregarded, and full consideration of environmental values is typically absent. The conventional mode of planning, based only on economic considerations, must give way to a new mode having due regard for the environment, in which plans are formulated and decisions are taken on the basis of broader natural and social criteria than heretofore (Bell, 1974).

The purpose of this paper is to outline an emerging mode of industrial planning into which environmental considerations are effectively integrated. This seems best derived from an application of concepts, principles, and methodologies, that are emerging in the fields of technology assessment (Coates, 1971; Jones, 1972; Hetman, 1973) and environmental impact assessment (Andrews, 1973b; Dickert, 1974, SCOPE, 1975), to the needs and requirements of industrial planning (Aharoni, 1966; Bower, 1970; Carter, 1971). The mode, as described, is oriented primarily towards the design of new projects (e.g. petroleum refineries, aluminium smelters, chemical plants, and so forth), but also could be applied in activities such as product selection, technology development, and transport system planning.

For the moment, such an environmentally-oriented mode of planning remains unorganized. It has not yet been formalized into doctrine by means of wide application and testing, and still lacks full coherence and cohesiveness in all of its detail. Nevertheless, enough thinking and evidence has emerged to indicate the probable overall configuration, key dimensions, and practical difficulties, of such a methodology of planning. This paper examines the currently 'unecological' (i.e. ignoring environmental consequences) nature of planning, demonstrates the need for change, outlines a new mode of planning in five dimensions, and identifies organizational and public-policy adjustments which might facilitate adoption of the new mode.

\section{CONVENTIONAL PLANNING WIDELY 'UNECOLOGICAL'}

The question of 'to what extent, and in what manner, have ecological considerations been incorporated into the corporate project planning processes of multinational corporations, and why?' was recently considered in a detailed study by one of us (Gladwin, 1975). Twenty-one recently-planned projects, ranging in cost from 35 million to 5.5 thousand million U.S. dollars, were investigated by means of interviews with executives of seventeen petroleum, chemicals, and metals, firms in nine different nations. A broad range of planning behaviour was discovered. At one end of this range were a few firms which appeared to be comprehensively taking ecological considerations into account. At the other end were many more which appeared to be indifferent to ecological concerns and were considering little beyond the immediate economic and technical aspects of their projects. The central conclusion of the research was that the practice of ecologically-oriented industrial project-planning is still in its infancy.

The process of project design in most firms was taking place in the absence of detailed ecological and social data on the site location. Baseline surveys of environmental conditions were typically done, if at all, only after approval had been received, construction activity had already begun, and the range of choice had been narrowed to a single favoured project-design. As a general rule, the incorporation of ecological considerations was found to be of a discontinuous nature, coming normally only at a late stage of pro-

Environmental Conservation, Vol. 2, No. 3, Autumn 1975-(C) 1975 The Foundation for Environmental Conservation-Printed in Switzerland. 
ject planning. Environmental science professionals were not significantly involved in many of the planning processes, and in others were brought in only at the last minute for 'credibility' purposes. Environmental impacts were typically compartmentalized; integrative and holistic thinking was rarely found. Few firms had conducted formal pre-project environmental impact assessments or made provisions for post-startup ecological impact monitoring. Many of the environmental studies that were performed appeared to be incomplete and done for purely 'cosmetic' purposes.

The reports of these studies were often viewed as vehicles for project promotion rather than as impartial analyses to be used in decision-making. Predominant planning attention was usually focused on issues of process-related residuals discharge, with only shallow attention directed to potential environmental consequences associated with other project actions such as construction and transportation. Most planning processes were typically secretive, exclusionist, and low-profile. The participation of potentially affected public bodies or interests was rarely solicited. For these and other reasons the current mode of planning was viewed as being 'unecological' (Gladwin, 1975).

\section{THE NEED FOR CHANGE}

While the maintenance or improvement of the environment cannot be expected to become a legitimate corporate objective in its own right, it can be justified by its contribution, however indirect, to profit, growth, and security. As recognized recently by both the Committee for Economic Development (1974) and the International Chamber of Commerce (1974), sound environmental planning is in the 'vested selfinterest' of industry-because it can have a long-run, if not a short-term, beneficial effect on profits. A review of over fifty cases of environmental conflict over industrial projects (Gladwin, 1975) suggests five economic reasons* why a mode of environmentallyoriented planning could be cost-effective:

1. Plant design and siting decisions that were once relatively simple, have become a matter of bewildering complexity and multiple pitfalls in which a relatively minor error can defeat a multi-million dollars project. As a few progressive firms have discovered, a careful and environmentally-oriented mode of planning can smooth the path for expansion-by helping to clear the countless social and environmental hurdles involved.

2. Environmentally-sound planning can help to reduce the chances of having a project blocked or rejected. A number of industrial projects have been halted recently, owing primarily to a failure to cope with environmentallybased objections. Integration of environmental concerns into planning at an early stage is likely to reduce the

* As was emphasized by a referee, the distinctions between these often seem to be obscure.-Ed. chance of cancellation as it gives planners the means of identifying, modifying, and mitigating, the sources of these objections.

3. Anticipatory environmental impact assessments can help to avoid the delays imposed when plans or project designs have to be reconsidered, because of possible environmental effects, at a late stage of the planning process. As countless firms have found out, delays can be costly-especially in terms of higher construction costs due to inflation, lost opportunities, and tied-up manpower.

4. Sound pre-project environmental planning can help to reduce the potential of intense and often protracted conflict episodes. The damaging publicity resulting from such episodes can have high costs in terms of community goodwill, public image, and employee morale.

5. Environmentally-oriented planning can help industrial concerns to avoid the additional costs required to rectify adverse environmental consequences 'after the fact'. Forced closings, major technological conversions, and claims for compensation from damaged parties, can be very expensive.

\section{AN ENVIRONMENTALLY-ORIENTED MODE OF PLANNING}

What constitutes an environmentally-oriented mode of planning? What kind of planning will best ensure avoidance of environmental damage? What kind of planning will help to smooth managerial paths by reducing the probability of delays, terminations, conflicts, forced closings, lawsuits, or major conversions? A common answer to all three questions is only beginning to emerge. It is certain that no magical or foolproof 'cookbook recipes' yet exist, and it seems possible that they never will exist. All that can be offered at this point in time is a tentative set of guiding principles and suggested procedures by which such a mode of planning might be achieved.

An environmentally-oriented mode of planning can be defined as one in which inputs and means related to environmental concerns, values, processes, conditions, and interrelationships, are continuously and carefully taken into account during planning. The objective of the mode is a more informed design of, and choice among, a range of alternative actions, such that adverse environmental consequences will be avoided or minimized. In the context of a new industrial project, the range of actions would include locations, input mixes, construction methods, scales of activity, process technologies, transport systems, output patterns, and so forth. The success of such a mode is gauged by how well the design of the project fits its environmental setting-or alternatively by whether, and, if so, to what degree, potentially adverse environmental consequences have been controlled.

The mode requires that the question of 'what impact would this action have on the physical and social environment?' be asked frequently and answered 
throughout the course of planning. The mode thus entails the continual acquisition, organization, and utilization, of knowledge-especially knowledge about the probable environmental consequences of alternative actions. Methodologies for accomplishing this task have recently come to be known as environmental impact assessment (Andrews, 1973a; Hetman, 1973; Dickert, 1974). The three basic analytic functions associated with impact assessment include description, prediction, and evaluation. Each function has associated with it a number of tasks. A visual model of the principal tasks that must be performed in environmental impact assessment, as adapted from Andrews (1973a) and Ortolano (1973), is given in Fig. 1.

As illustrated in Fig. 1, eight principal tasks are involved in the process of environmental impact

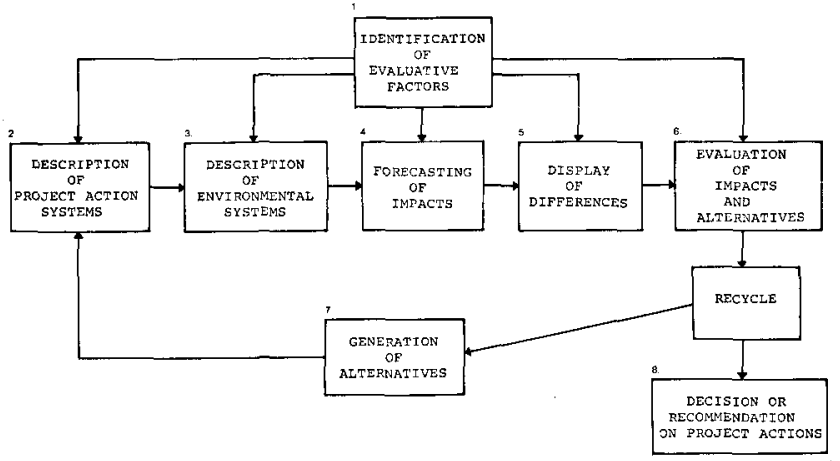

FIG. 1. The principal tasks involved in environmental impact assessment. It should be noted that the description of "environmental systems' is (and will probably always remain) incomplete and to some extent simplistic, so that only impacts which are predictable from known phenomena can be forecast.

assessment. Tasks 2-8 are all shaped by what Ortolano (1973) terms 'evaluative factors'. These denote the issues, concerns, goals, or socially-valued factors, that should serve as criteria in performing the assessment. These factors, which need to be considered in such activities as generating alternatives, describing systems, and forecasting impacts, can be derived from many sources-including corporate objectives, public input, legal and legislative requirements, and technical considerations. Tasks 2 and 3 are both concerned with systems description: projects need to be viewed as packages, or systems of actions, from which different kinds of environmental impacts may result (Andrews, 1973b). The environmental systems into which the project actions are being introduced need to be modelled, and interrelationships need to be described. Task 4 involved the forecasting of the changes or modifications in environmental systems which may reasonably be expected to result from the introduction of the project actions. Changes in the environment need to be forecast in terms of their magnitude, quan- tity, probability, timing, and spatial dimensions. Task 5 displays the differences among alternative actions and their associated impacts. This is done in preparation for task 6 , which is the evaluation of these differences in terms of their desirability. If the actions are deemed undesirable, task 7 , involving the generation of further alternative courses of action, becomes essential. Of course with new alternatives there will come another run through tasks 2-6-hence the boxed and unnumbered 'RECYCLE' in Fig. 1. At some point task 8, involving a decision or recommendation on which of the alternative sets of actions should be adopted, is finally reached.

\section{DIMENSIONS OF AN ENVIRONMENTALLY-ORIENTED MODE OF PLANNING}

The tasks of environmental impact assessment in their full iterative sequence form the thought process which lies at the heart of environmentally-oriented planning. The practical question is, how can such a thought process be effectively built into the planning process? The answer appears to be a multidimensional one: inputs and means can be injected into the planning process in a number of dimensions, to facilitate the attainment of an overall environmentally=oriented mode. Under the following side-headings we will now identify five interdependent dimensions (or guiding principles) which can contribute to an environmentally-oriented mode of planning. The logic, operational procedures, and practical difficulties, associated with each dimension, are also presented.

\section{Multidisciplinary Professional Involvement}

This dimension is concerned with the nature and range of the environmentally-oriented participant skills and competencies that are utilized in planning. Sound planning, which must cover a broad range of environmental concerns, requires the input of experienced, multidisciplinary, and really professional, judgment. The involvement of a variety of professionals with different, but relevant, backgrounds (e.g. in ecology, biology, sociology, geography, landscape architecture, political science, etc.) will inculcate enhanced awareness as well as knowledge of environmental concerns. The infusion of such professionals, who possess varying perceptions, memories, values, and commitments, will also serve to extend the degree of search and increase the diversity of alternatives considered-by helping to take off the 'mental blinkers' associated with conventional engineering and economic expertise.

Multidisciplinary expertise can be acquired by either creating an 'in-house' pool of specialized professionals or by drawing on external consultants; the latter option helps to guard against the 'insider view- 
point.' The creation of multidisciplinary impact assessment study-teams with an interdisciplinary perspective, represents an especially useful approach (Ortolano, 1973). The problems of attaining multidisciplinary cooperation and interdisciplinary synthesis, however, are formidable (McEvoy, 1972). There are numerous barriers-including the traditional compartmentalization of disciplines, problems of integrating heterogeneous data, communication gaps due to different terminologies and methodologies, and complex issues of interpersonal dynamics.

\section{Broad Public Participation}

This dimension is concerned with efforts that should be expended in order to obtain the views of, and to inform, the public bodies or interests which may be directly or indirectly affected by the project. Planning which is to be really anticipatory and sympathetic, will require broad and extensive participation in its process by those whose preferred uses of environmental resources might be affected by the project (Smith, 1973). The advantages of such participation can be substantial: for (1) it can provide the planning process with immediate and accurate information and judgements regarding local systems, (2) it can produce evidence that will assist in identifying alternatives and appropriate actions, (3) it can be a positive factor in the acceptance of the project and thus facilitate project implementation, and (4) it can help minimize the chances of confrontation and delays.

As is shown in Table I, which is adapted from the work of Bishop (1973), the techniques of facilitating public participation are multifarious. The techniques vary in terms of level of public contact achieved, the degree of two-way communication, and the ability to handle specific interests. They are all, however, means of opening up the planning process for the positive inclusion of citizen input.

\section{TABLE I}

\section{Selected Techniques of Public Participation and Communication.}

1. Hiring locally-based consultants

2. Conducting surveys of local perceptions

3. Public hearings and meetings

4. Informal small-group meetings

5. General public information meetings

6. Presentations to community organizations

7. Information-coordination seminars

8. Operating a local information office

9. Information brochures and pamphlets

10. Trips for citizens to existing facilities

11. Organized tours of site location for citizens

12. Public displays and models of project

13. Materials for mass media
14. Responses to public inquiries

15. Press releases inviting comments

16. Letter requests for comments

17. Citizen advisory committees

18. Joint task-forces and workshops

19. Employment of community residents

20. Public review of environmental impact studies

21. Attendance at local planning meetings

22. Community interests advocate

23. Creating educational programmes for students

24. Creating citizen inspection-groups.

Enhanced public participation in industrial planning will not be easy to achieve, and will not represent a cure-all. It is generally perceived by conventional planners as being time-consuming, tedious, costly, and risky. Getting people's attention, and holding it over long planning-periods without the setting in of boredom and frustration, involves considerable problems. The difficulties of effectively communicating to laymen the often detailed and significant technical information involved are only too well-known.

Achieving a necessary long-term perspective when the affected public bodies are overwhelmingly concerned about short-run impacts, represents a further complication. Moreover, as there is a very fine line of division between perceived participation and co-optation, the likelihood that feelings of resentment and dissatisfaction may set in is high. In spite of these difficulties, the pluralist uprisings which are currently taking place in many nations signal that a 'closed' mode of planning will soon be no longer viable. 'Open' planning will be necessary, and the practical problem will be to devise methods for actively including affected citizens, keeping them well informed, and giving them a chance to affect the planning process, while preserving the degree of control required for orderly planning operations.

\section{Holistic Thinking}

This dimension is concerned with the scope of environmental factors to be considered during the course of planning. As large-scale industrial projects usually consist of complex systems of related actions from which different kinds of environmental impacts will result, sound planning will require a comprehensive viewpoint as a basis. The full range of impact-causing preconstruction, construction, transport, raw materials, product output, residuals output, and inducing actions, taken both individually and as a total system, will need to be attended to. The components of the environmental system into which the project is to be introduced, will also need to be comprehensively and holistically studied. Planners will need to capture accurately the interrelationships and structures of these complex systems-because impacts affect systems, not just discrete resources or biological species (Andrews, 1973b). 
Full comprehensiveness, in the sense that all linkages and all project action alternatives are considered, will of course never be possible, because of the great costs of time and information needed and of various elements of uncertainty. Planners will be faced with many difficult decisions on how to allocate analytical time and attention. One kind of decision that will need to be made repeatedly, will be that of which of the given alternative actions and impacts should be assessed. Deciding which of these should receive attention, and in what detail, will depend on the acknowledged constraints, inventiveness, and professional judgements, of planners, on the cost in time and money, on the concerns of potentially affected public bodies, and ultimately on the perceived importance of the project.

The use of sensitivity analysis to pin-point the most critical environmental concerns, and the use of screening procedures which progressively examine alternatives and their impacts in greater detail as the planning process proceeds, may be useful techniques to employ. As the project planner will naturally be confronted with many uncertainties owing to scarce information and limitations in the predictions of outcomes, another difficult decision will be to select which uncertainties to attempt to reduce. Decisions here will depend on many of the factors mentioned above. They will also depend on the significance of the uncertainties and on estimates of the extent to which further study could help to reduce the uncertainties in question (Andrews, 1973b).

\section{Systematic Analysis}

This dimension is concerned with the utilization of systematic analytical techniques and procedures in the consideration of environmental factors during planning. An objective understanding of the consequences of project actions can probably best be achieved through the use of structured and rational techniques. Environmental impact information should be gathered, organized, analyzed, and displayed in a form that will be conducive to effective use in project design decisionmaking.

Table II shows a wide variety of techniques which are potentially applicable to use in environmentallyoriented planning. This list has been culled from the survey literature on technology and environmental impact assessment (Andrews, 1973a; Hetman, 1973; Dickert, 1974). Techniques are available for use in all of the three analytical functions of the assessment process, namely systems description, impact prediction, and impact and alternatives evaluation. A selection under each of these headings is given in Table II.

Most of the available techniques, however, are crude. In addition, most have not been widely tested or applied in the context of project-impact assessment. The devel-
TABLE II

\section{Selected Techniques of Environmental Assessment.}

\section{DESCRIPTION}

1. Pre- and post-startup measurements of environmental conditions.

2. Check-lists identifying the environmental conditions and causative actions to be considered.

3. Transparencies of environmental conditions overlaid on regional base-maps.

4. Cause-effect matrices relating causative actions to environmental components in a first-order, one-way fashion.

5. Network of flow diagrams showing relationships among causative actions, environmental components, and expected impacts.

\section{PREDICTION}

1. Assembly of expert judgement and consensus (e.g., Delphi technique, expert position-papers, etc.).

2. Extrapolation or projection of existing trends.

3. Written narrative scenarios which describe expected future states.

4. Cross-impact matrices relating components in the analysis by means of two-way linkages and feedbacks.

5. Manipulation of mathematical simulations (models) of the action-component-impact systems.

\section{EVALUATION}

1. Narrative or graphic displays of differences in impacts (i.e., trade-offs) among alternatives.

2. Enumeration and analytic study of all relevant costs and benefits in identifying preferred choices.

3. Assignment of numerical weights to factors and creation of aggregate indexes of environmental impact for alternative actions.

4. Sensitivity testing of the outcomes of the analysis for changes in the assumptions or values of the input variables.

5. Comparision of alternative actions and impacts with established standards, community acceptance, and natural system suitability.

opment of integrated sets of techniques for the total sequence of tasks involved in the assessment process is only just beginning. Certain critical techniques, such as dynamic natural-system modelling, are only now starting to emerge (Kneese, 1973). The absence or relative paucity of scientific knowledge that is available for use in the techniques is also a complicating factor. This should not be overemphasized, however, because there is a great and immediate need for effective application of environmental principles that are already known. The difficulties of having only rather crude tools and imperfect knowledge imply that environmental assessment can currently be considered as more an art than a form of real applied science. The needs for, and importance of, performing such assessments, however, are such that attempts to deal with this problem cannot be deferred on account of its difficulty. It is necessary to get on the 'learning curve', 
and to grapple, however imperfectly, with the tools and data that are currently available.

\section{Continuous Integration}

This dimension is concerned with the temporal integration of environmental considerations into the various phases of planning. Sound planning requires that the thought-process of impact assessment be fully integrated into planning from the very start. This is necessary because decision points, involving a balancing of environmental and non-environmental factors, are scattered from the very beginning to the very end of the planning process. The most critical need is for early integration. Early consideration of environmental impact will avoid overlooking critical factors, allow incorporation of critical design-features, enhance the likelihood of acceptance of the plans that are developed, stimulate wider consideration of alternatives, and protect basic environmental components (Fischer \& Francis, 1974).

The evolutionary process of project design, which in its formative stages involves general and broadranging ideas, but which becomes progressively narrower when concerned with a specific, clear-cut proposal, will need to be matched by a process of impact assessment that is performed at increasing levels of detail throughout the planning process. The foremost implication of continuous integration is that the time needed for obtaining environmental information, interacting with affected public bodies, and analyzing and evaluating impact predictions, will need to be built into the scheduling and budgetary requirements of project planning. Extending the degree of search, and increasing the diversity of alternatives considered, will of necessity lengthen the planning period--but not unduly, if environmental considerations are introduced as early as possible.

\section{FACILITATING ENVIRONMENTALLY-ORIENTED PLANNING THROUGH ORGANIZATIONAL CHANGE}

How can adoption of an environmentally-oriented mode of planning, as outlined above, be encouraged or facilitated by the top managements of industrial firms? As has been found by organizational research workers, the path of the planning process may be swayed by a number of variables (Aharoni, 1966; Bower, 1970; Gladwin, 1975). These variables can be viewed as 'points of leverage' which managements have at their disposal to influence the inputs, means, and inevitably the outputs, of the planning process. These leverage points define the 'rules of the game' under which planning is carried out. Five of the potentially most powerful organizational leverage points are shown in Fig. 2.

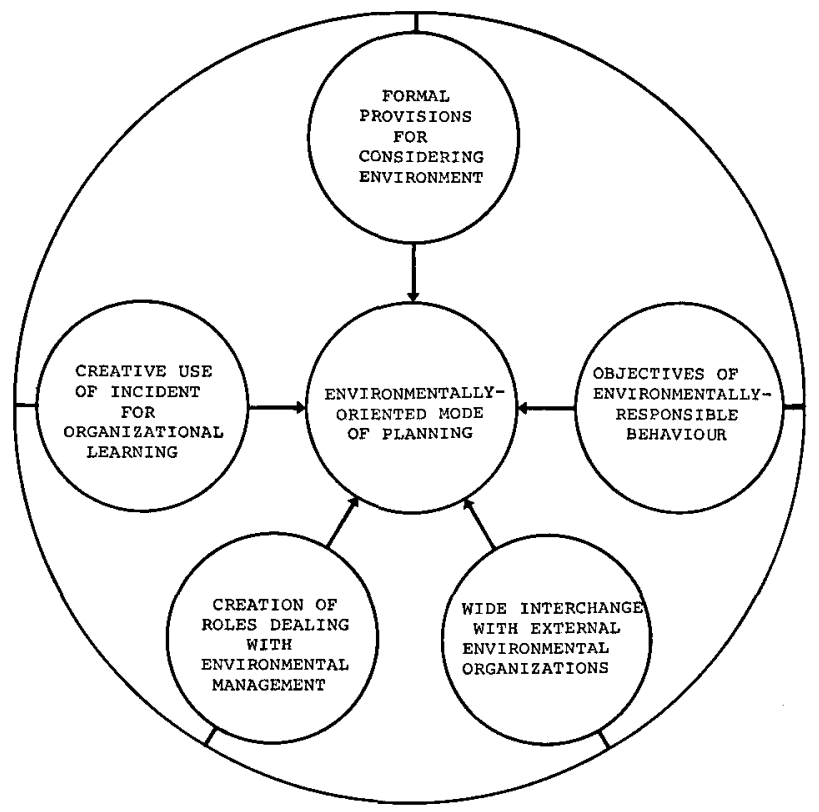

Fig. 2. Organizational changes that may facilitate an environmentally-oriented mode of planning.

If environmental assessment in the context of project planning is to be careful and conscientious, formal rules and procedures will probably be needed for guiding the effort. An active consciousness of environmental considerations will be achieved only when action-forcing provisions are introduced to hold project planners accountable for their decisions. In short, the attention of planners will be focused on environmental impact problems only when they clearly perceive that resource-allocation decisions and their careers depend on it. A number of action-forcing mechanisms, including internal impact statement requirements, project reviews by environmental staff and top management, and environmental performance evaluations of planners, are now available. When first introduced, these mechanisms may be frightening to conventional planners; they will therefore need to be clearly and strongly communicated, and consistently supported, by top management.

Aharoni (1966) has found that the perceptions held by planners of the factors which are important to top management will commonly influence the way in which they plan a project. He also found that modifications are usually made in projects to ensure that they are in accord with existing corporate objectives and policies. The implications of these findings are that planning will be environmentally-oriented only when the firm's objectives for environmentally-responsible behaviour are deep-seated, consistently supported by top management, and backed up by reinforcing performance measurement and reward systems (Anshen, 1974). When environmental management objectives are held only weakly by the firm, project planners wil 
tend to be subject to the many vagrant pressures, from within and without the firm, to disregard concerns of environmental impact. Yet objectives of environmentally-responsible behaviour represent positive resources for planners, because they clearly depict the desired state of affairs which the firm is trying to realize in the long term.

Environmentally-oriented planning will be greatly facilitated when the firm as a whole engages in a wide and deep interchange with its external surroundings, and particularly with organizations concerned with environmental protection. Sensitive external scanning and extensive interorganizational relations are key sources for the continuous introduction of variety into the firm's information system. Greater openness allows more feedback of the satisfactions and intentions of external reference groups, more exposure to new ideas of environmental conservation, and more observational learning from the experiences of other firms. Greater openness also provides the firm with greater access to environmental knowledge and professional expertise. Organizational adjustments which serve to increase the firm's sensitivity to external change should thus be conducive to environmentally-oriented planning.

Provided it remains fully objective, the creation, within a firm or other organization, of new roles or positions concerned with environmental management, will create forces which lead planners to plan in environmentally-oriented ways. Creation of roles such as 'corporate environmental coordinator' or 'project environmental adviser' will serve to redistribute influence and give emphasis to different values within the organization. The assignment of environmental roles, which by their very nature are externally oriented, will enable the firm to be more sensitive to its surroundings than formerly. And as these specialists are likely to be heavily influenced by ideas generated within their science or profession, establishment of their roles will create a new source of innovative inputs. The presence of 'environmental managers' may serve to institutionalize the advocacy of environmental values and to catalyze a new set of internally-shared attitudes which will be increasingly sympathetic to environmental concerns. Suitably qualified and experienced environmental professionals, however, are currently in short supply (Polunin, 1974). More are urgently needed, and the encouragement, by industry, of more and better programmes of university training in the field of environmental management could be especially helpful.

The matter of role creation raises the question of how companies should best go about organizing for environmental management. Recent research (Hopkinson, 1970; Welles, 1973; Wheelwright, 1973; Lund, 1974; Gladwin \& Welles, 1975) has shown that the practical answer for any one company depends on a number of factors. These include the size of the organ- ization, nature and range of activities impacting on the environment, managerial philosophy, existing organizational structure, extent of international operations, stage of motivation of company employees, intensity of external pressures, and nature of communication within the company's industry. Three general principles, however, have seemingly emerged.

First, the responsibility and authority for environmental management must rest with the firm's 'line' management-under its project, production, and transportation, managers. These are the executives who ultimately must integrate environmental considerations into their decision-making, and balance these factors against the often conflicting economic and engineering factors involved. Second, these line managers should be encouraged and assisted in their efforts by 'staff' environmental science professionals. Some of these specialized professionals can be grouped into central units for coordination purposes (e.g. 'Environmental Control Centre', 'Office of Environmental Affairs', etc.) but most should perhaps be 'closer to the action' - dispersed throughout all of the firm's functional, geographical, and operating, departments where decisions affecting the environment are made. Third, the efforts of both the line managers and staff advisers can be 'catalyzed', guided, and coordinated, by policies formulated by senior management environmental committees. In short, the job of corporate environmental management cannot be delegated to a centralized group of so-called 'environmental managers'. Every decisionmaker in the firm should be concerned with issues of environmental impact; his concern, however, can be guided by policies from top management and by advice from staff professionals.

One final leverage point might be the creative use of a conspicuous incident (e.g. a project which has been blocked or severely delayed owing to obviously poor environmental planning) as a corporate learning experience. This may represent the most effective way of emphasizing the 'relative advantage' of environmentally-oriented planning. Top management could creatively intervene in the incident, using it as a test case to set a well-established precedent regarding the need for a new mode (Ackerman, 1973). Intervention by top management would serve to signal forcefully the presence of a recognized 'performance gap' which would set in motion a search for innovative planning methods capable of reducing the well-perceived organizational deficiency.

\section{FACILITATING ENVIRONMENTALLY-ORIENTED PLANNING} THROUGH PUBLIC POLICY CHANGE

Just as top management can manipulate pressurepoints within the firm, so too can public policy-makers utilize points of leverage outside the firm in order to 
encourage or facilitate adoption of an environmentallyoriented mode of planning. The ultimate aims of public policy intervention should be project-planning outcomes that are in the long-range 'public interest', and that are arrived at by procedurally equitable means. Achieving these aims requires a refashioning of the incentive systems which guide economic decisionmaking in the private sector of society. Many leverage points or intervention techniques can be enumerated, but it is not practicable or even possible to establish priorities among them that are applicable to all countries. Differences in environmental needs, social systems, and political systems among nations, imply that differences in institutional arrangements are necessary and desirable. Five general techniques which might be considered, however, are indicated in Fig. 3.

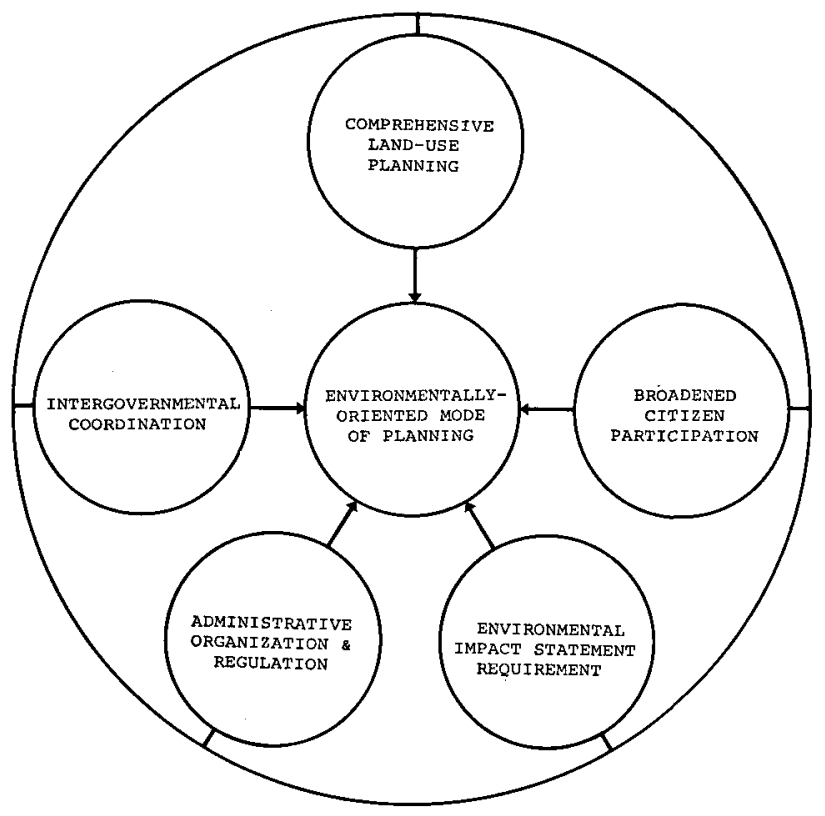

FIG. 3. Public policy changes that may facilitate an environmentally-oriented mode of planning.

The long-term key to environmentally-sound planning probably rests with broadened control over landuse (McAllister, 1973). Environmentally-oriented industrial siting decisions cannot be properly made, and project impact assessment cannot be properly conducted, without a wide basis of regional land-use data and criteria. A comprehensive master-plan of future land-use can be of considerable value to planners, allowing them to determine how their proposed project might or might not fit in.

Broadened citizen participation in the planning and approval process of industrial projects that are subject to higher administrative approval, represents a powerful mechanism for helping to assure responsive and responsible decisions (Mitnick \& Weiss, 1974). Public hearings can be a useful technique, because they pro- vide a focus for affected groups, serve to marshal and elucidate the available information, and require firms to articulate and explain the basis of their environmental impact judgements. Broadening the citizen's right to bring legal suit against, and the scope of a court's authority to review, industrial plans which are likely to impair environmental quality, has been found in some nations to represent a powerful lever for bringing about more environmentally-congenial industrial behaviour-patterns (Sax, 1970).

Requiring formal environmental impact statements to be written for proposed projects, has been found in a few countries (e.g. the United States, Canada, and Australia) to be an especially useful device for making the industrial planning process more responsive to environmental considerations and values (Anderson \& Daniels, 1973; SCOPE, 1975). The impact statement requirement could fruitfully be made a part of the already existing project-screening and -approval procedures of regulatory agencies in other nations.* The statement requirement, however, is no panacea for ensuring that industrial or governmental projects will have a minimally adverse effect on the environment; it merely increases the probability that planners will have considered matters beyond the immediate economic and technical aspects of the proposed project (Kreith, 1973; Dickert \& Sorenson, 1974).

Another factor that appears to influence the behaviour of industrial planners is the presence of effective organization and regulation of governmental activities for environmental protection (Caldwell, 1974). The creation of policy-making and policy-implementing organizations serves to promote the advocacy of environmental considerations within a nation quite visibly and forcefully. Comprehensive, adaptive, and scientifically capable, administrative machinery possessing strong enforcement powers, can be a strong motivator of environmentally-oriented planning behaviour.

Finally, better coordination among the great number and range of government agencies that are typically concerned, in one way or another, with the assessment of a new industrial project, might serve to expedite a more environmentally-oriented planning process. In most nations, jurisdiction over the environmental effects of a major industrial project is widely scattered. Fragmentation in project regulation is not only costly, tedious, and time-consuming for the firm, but also tends to work against comprehensive environmental impact-assessment. In many instances, an agency is only concerned with one piece of the project, and gives its approval or disapproval without seeing the total picture. Lacking the resources for an adequate investi-

* In some countries the conduciveness to bribery and corruption in the governmental project-approval process would seem likely to render such a system ineffective.-Ed. 
gation, it often tends to make its decisions on the sole basis of evidence presented by the interested parties. Better intergovernmental coordination would facilitate a pooling of resources in making an investigation, and also inculcate a desirably comprehensive and holistic perspective.

Alfred North Whitehead (1961) once said: 'Systems, scientific and philosophic, come and go. Each method of limited understanding is at length exhausted. In its prime each system is a triumphant success; in its decay it is an obstructive nuisance.' The conventional industrial planning process which ignores the human environment is one such decaying system.

\section{ACKNOWLEDGEMENTS}

The authors express their warm appreciation of, and indebtedness to, the following institutions which supported the research on which this article is based: Tenneco Inc., Centre d'Etudes Industrielles (C.E.I.), and the Institute for International Commerce in the Graduate School of Business Administration of the University of Michigan. The views expressed are, of course, those of the authors alone, and do not necessarily represent the views of the supporting organizations identified above.

\section{SUMMARY}

Recent research has shown that many industrial projects are not being designed with the environment in mind. The intellectual exercise of thinking 'what impact does this project have on the environment?' has not yet been made an integral part of industrial project-planning. More thoughtful and informed planning is needed, for reasons of both sound environmental management and, increasingly, sound project economics. An environmentally-oriented mode of planning, in which inputs and means related to environmental concerns are carefully taken into account during the planning, is discussed. This mode represents a tentative summary statement of an emerging consensus. Its objective is to facilitate informed and socially desirable choice among alternative actions in such a manner that adverse environmental consequences will be avoided or at least minimized.

Environmentally-oriented planning requires that a new methodology, that of impact assessment, be fully integrated into the very fabric of planning. Impact assessment consists of three analytical functions: description, prediction, and evaluation. These functions can be translated into a series of tasks, which in their entirety constitute the full process of impact assessment. The process can be achieved operationally by incorporating environmental considerations into planning via five dimensions: multidisciplinary professional involvement, broad public participation, holistic thinking, systematic analysis, and continuous integration. Adoption and application of the process can be encouraged and/or facilitated by a number of internal organizational adjustments, or by external public-policy adjustments.

\section{References}

ACKerman, Robert W. (1973). How companies respond to social demands. Harvard Business Review, 51, pp. 88-98.

Aharoni, Yair (1966). The Foreign Investment Decision Process. Division of Research, Graduate School of Business Administration, Harvard University, Boston, Massachusetts: xvii +362 pp.

ANDERson, Frederick R., assisted by DANIELs, Robert H. (1973). NEPA in the Courts: A Legal Analysis of the National Environmental Policy Act. Johns Hopkins University Press, (for Resources for the Future) Baltimore, Maryland: $\mathrm{xv}+324 \mathrm{pp}$.

ANDREws, Richard N. L. (1973a). Approaches to Impact Assessment: Comparison and Critique. Paper presented at the Short Course on Impact Assessment in Water Resource Planning, 9 June 1973, School of Natural Resources, University of Michigan, Ann Arbor, Michigan: 46 pp., illustr. (mimeogr.).

ANDREWs, Richard N. L. (1973b). A philosophy of environmental impact assessment. Journal of Soil and Water Conservation, 28, pp. 197-203.

ANSHEN, Melvin (1974). The socially responsible corporation: from concept to implementation. Pp. 1-22 in Managing the Socially Responsible Corporation (Ed. Melvin Anshen). Macmillan, New York, N.Y.: x + 256 pp.

BeLL, Daniel (1974). The Coming of Post-industrial Society: $A$ Venture in Social Forecasting. Heinemann, London, England: xiii $+507 \mathrm{pp}$.

Bishop, A. Bruce (1973). Public Participation in Environmental Impact Assessment. Paper presented at the Engineering Foundation Conference on Preparation of Environmental Impact Statements, 29 July-3 August 1973, New England College, Henniker, New Hampshire: 21 pp. (mimeogr.).

Bower, Joseph L. (1970). Managing the Resource Allocation Process: a Study of Corporate Planning and Investment. Division of Research, Graduate School of Business Administration, Harvard University, Boston, Massachusetts: $\mathrm{xV}+363$ pp., illustr.

BrubaKer, Sterling (1972). To Live On Earth: Man and His Environment in Perspective. A Resources for the Future Study. Mentor Books, New York, N.Y.: xx $+253 \mathrm{pp}$.

CALdwell, Lynton K. (1972). In Defense of Earth: International Protection of the Biosphere. Indiana University Press, Bloomington, Indiana: $\mathrm{x}+295 \mathrm{pp}$.

Caldwell, Lynton K. (1974). Organizational and administrative aspects of environmental problems at the local, national, and international levels. Pp. 12-36 in Organization and Administration of Environmental Programmes. ST/ESA/16, United Nations Department of Economic and Social Affairs, New York, N.Y.: v + 187 pp.

Carter, E. Eugene (1971). Project evaluations and firm decisions. Journal of Management Studies, 8, pp. 253-79.

CoAtes, Joseph F. (1971). Technology assessment : the benefits... the costs... the consequences. The Futurist, 5, pp. 225-31.

COMmittee for Economic Development (1974). More Effective Programs for A Cleaner Environment. A Statement on National Policy by the Research and Policy Committee, Committee for Economic Development, New York, N.Y.: 74 pp. 
COMmoner, Barry (1971). The Closing Circle: Nature, Man, and Technology. Bantam Books, New York, N.Y.: 343 pp.

DiCKERT, Thomas G. (1974). Methods for environmental impact assessment: a comparison. $\mathrm{Pp} .127-43$ in Environmental Impact Assessment: Guidelines and Commentary (Ed. Thomas G. Dickert with Katherine R. Domeny). University Extension, University of California, Berkeley, California: $\mathrm{xi}+238$ pp., illustr.

Dickert, Thomas G. \& Sorenson, Jens C. (1974). Some suggestions on the content and organization of environmental impact statements. Pp. 35-53 in Environmental Impact Assessment: Guidelines and Commentary (Ed. Thomas G. Dickert with Katherine R. Domeny). University Extension, University of California, Berkeley, California: xi $+238 \mathrm{pp}$,, illustr.

Fischer, D. W. \& Francis, G. R. (1974). Water resource development and environment: an approach to impact analysis. International Journal of Environmental Studies, 5, pp. 299-305.

Gladwin, Thomas N. (1975). The Role of Ecological Considerations in the Multinational Corporate Project Planning Process : A Comparative Study of North American- and Western European-based Petroleum, Chemicals and Metals Firms. Unpublished Ph.D. dissertation, Graduate School of Business Administration, University of Michigan, Ann Arbor: xiv +547 pp., illustr.

Gladwin, Thomas N. \& Welles, John G. (1975). Environmental Policy and Multinational Corporate Strategy. Paper prepared for the Ford Foundation Symposium on the International Economic Dimensions of Environmental Management, 17 April 1975, New York University, New York, N.Y.: 60 pp., illustr. (mimeogr.).

Hetman, François (1973). Society and the Assessment of Technology. Organization for Economic Cooperation and Development, Paris, France: 420 pp., illustr.

Hopkinson, Richard A. (1970). Corporate Organization for Pollution Control. Conference Board, New York, N.Y.: ii $+72 \mathrm{pp}$.

INTERNATIONAL Chamber of COMmerce (1974). Environmental Guidelines for World Industry. Document No. 210/59, International Chamber of Commerce, Paris, France: 7 pp. (mimeogr.).

JONES, Martin V. (1972). The methodology of technology assessment. The Futurist, 6, pp. 19-26.

KAPP, K. William (1970). Environmental disruption and social costs: a challenge to economics. Kyklos, 23, pp. 833-48.

KNEESE, Allen V. (1973). Management science, economics, and environmental science. Management Science, 19, pp. 112237.
KREITH, F. (1973). Lack of impact: environmental impact statements. Environment, 15, pp. 26-33.

Lund, Leonard (1974). Corporate Organization for Environmental Policy Making. Conference Board, New York, N.Y.: 50 pp.

MCAllister, Donald M. (Ed.) (1973). Environment: A New Focus for Land-use Planning. RANN-Research Applied to National Needs, National Science Foundation, Washington, D.C.: xvi + 328 pp., illustr.

McEvoy, James, III, (1972). Multi- and interdisciplinary research-problems of initiation, control, integration, and reward. Policy Sciences, 3, pp. 201-8.

Mitnick, Barry M. \& Weiss, Charles, Jr (1974). The siting impasse and a rational choice model of regulatory behavior: an agency for power plant siting. Journal of Environmental Economics and Management, 1, pp. 150-71.

Ortolano, Leonard (1973). Impact Assessment in Water Resources Planning. Paper presented at the Short Course on Impact Assessment in Water Resource Planning, 4 June 1973, School of Natural Resources, University of Michigan, Ann Arbor, Michigan: 30 pp., illustr. (mimeogr.).

PoluniN, Nicholas (as N.P.) (1974), Whither ecologists? Environmental Conservation, $1(2), \mathrm{p} .82$.

SAX, Joseph L. (1970). Defending the Environment: A Handbook for Citizen Action. Vintage Books, New York, N.Y.: $\mathrm{xix}+252 \mathrm{pp}$.

Scientific Committee on Problems of the Environment (cited as SCOPE) (1975). Environmental Impact Assessment : Principles and Procedures. SCOPE Workshop on Impact Studies in the Environment... Report No. 5, SCOPE, Toronto, Ontario: 160 pp., illustr.

SмITH, Richard Warren (1973). A theoretical basis for participatory planning. Policy Sciences, 4, pp. 275-95.

Strong, Maurice F. (1973). One year after Stockholm: an ecological approach to management. Foreign Affairs, 51, pp. $690-707$.

WARD, Barbara \& Dubos, René (1972). Only One Earth: The Care and Maintenance of $A$ Small Planet. Penguin Books, Middlesex, England: 304 pp.

WELLES, John G. (1973). Multinationals need new environmental strategies. Columbia Journal of World Business, 8, pp. 11-8.

WHEELWRIGHT, Steven C. (1973). Developing a corporate response to pollution control. European Business, No. 38 , pp. 64-72.

Whitehead, Alfred N. (1961). Adventures in Ideas (16th Printing). Macmillan, New York, N.Y.: xii +392 pp.

\section{INTECOL Joins Up}

Although distribution only started slightly over a year ago, it is already being said that our Journal is becoming a familiar sight in concerned circles all over the world. This will presumably mean that people will no longer be looking at the cover but will rush (we hope) to see what is inside! However, those who do look at the front cover will find a change from this issue onwards-the addition of the
International Association for Ecology (INTECOL) to the short and special list of our 'institutional' collaborators. On the reverse side of the front cover our distinguished panel of Advisory Editors is now graced with an INTECOL representative-their President, Professor Amyan Macfadyen, of the New University of Ulster, Coleraine, Northern Ireland, whom we welcome most warmly. 